\title{
Arc Characteristics and Welding Process of Magnetic Field Assisting Plasma-GMAW-P
}

\author{
Plasma-GMAW-P arc profile, temperature field, and welding process \\ at the different external magnetic fields were investigated
}

BY J. YU, H. ZHANG, X. YANG, Y. TENG, Q. WANG, L. WEI, P. HE, AND W. ZHANG

\begin{abstract}
Low-carbon steel Q235B was successfully joined by plasma-pulsed gas metal arc welding (plasma-GMAW-P) with an external magnetic field. The arc profile, temperature field, electrical signal, microstructure, and mechanical properties of this method were analyzed. The results indicated that the coupling degree of the two arcs increased with the strengthening of the magnetic field current. However, when the magnetic field current was greater than $1 \mathrm{~A}$, the arc profile changed slightly with the increase of the magnetic field current. Fixed on the magnetic field current, the coupling degree first increased and then decreased with the increase of the plasma welding current, GMAW-P welding current, plasma gas flow rate, and nozzle height, respectively. The maximum temperature had no obvious influence on joint penetration at different magnetic field currents. However, the average temperature had an inverse effect on joint penetration at different magnetic field currents. The weld fusion zone joint tensile test results showed that the ratio of depth to width increased with the application of magnetic field currents. Moreover, tensile strength on the upper and lower part of the tensile samples were 521 and $488 \mathrm{MPa}$, respectively, which were $4.6 \%$ and $3.2 \%$ higher than those without the magnetic field. The microhardness of the weld joints was higher than that without the magnetic field.
\end{abstract}

\section{KEYWORDS}

- Plasma-GMAW-P • Arc Profile • Coupling Degree

- Magnetic Field Current • Tensile Strength

\section{Introduction}

Laser beam welding (LBW), electron beam welding (EBW), and plasma arc welding (PAW) are considered as high-power-intensity heat source welding methods due to the function of the keyhole mode, which promotes deep penetration and enhances mechanical properties (Refs. $1-3)$. Due to the welding equipment costs, PAW is more widely applied in various industries to join different materials than LBW and EBW (Refs. 4-6). Gas metal arc welding (GMAW) has the features of high deposition and a wider process zone as well as lower power density, which allows extensive application in the industrial field (Refs. 7, 8). Hybrid arc welding methods have been regarded as effective in improving joint properties in the scope of welding (Ref. 9). A series of hybrid welding technology for the aforementioned methods is performed, such as plasma-GMAW (Ref. 10) and double-electrode GMAW (DE-GMAW) (Ref. 11). DE-GMAW achieves the welding process of double wires located in the same molten pool, which improves welding speed and productivity (Ref. 12). There is a 7.5-deg angle between two respective wire electrodes and the vertical, and the distance between the electrode tip spacing is $9 \mathrm{~mm}$ (Ref. 13). Therefore, two wires operate close in the torch and may render magnetic interaction. Pulsed GMAW (GMAW-P) could achieve a stable welding process by droplet transfer with one drop per pulse, and pulsed mode is applied to this method to minimize magnetic interaction, which is claimed as doublepulsed GMAW (DP-GMAW) )(Ref. 14).

Hybrid arc profiles and their interactions have an important effect on the hybrid welding process and weld quality. Liu et al. studied the DP-GMAW arc profile variation process and found that the arc profile variation and droplet transfer in the thermal peak were higher than in the thermal base, but the variance of arc size in the thermal peak was opposite (Ref. 15). Schnick et al. analyzed arc interactions and their influence on the gas shield flow in the DP-GMAW process, which enhanced the understanding of the causes of periodic instabilities and joint imperfections (Ref. 13). Wu et al. investigated the double arc interaction and quantitative analysis of double arc offset of DP-GMAW and felt that electromagnetic field, arc pressure, and arc stiffness had important effects on arc offset behavior (Ref. 16). 


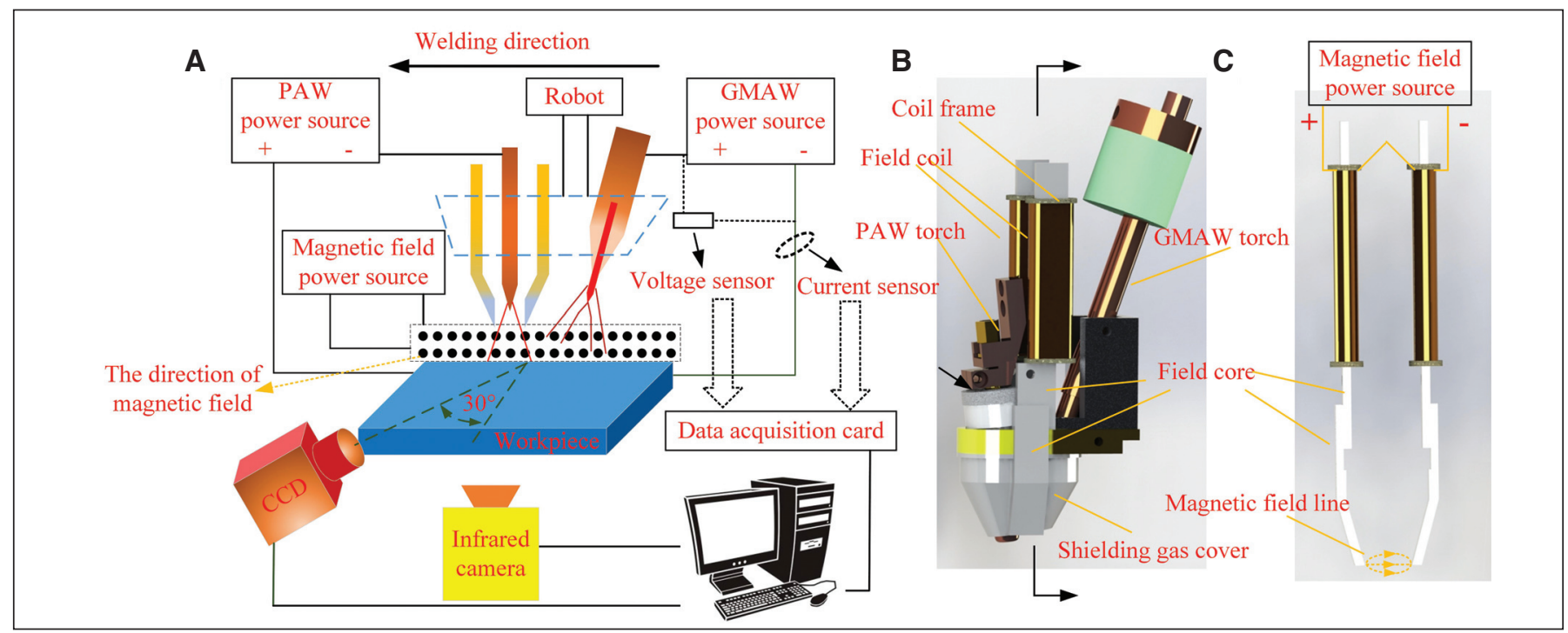

Fig. 1 - Experimental setup. A - Schematic diagram of plasma-GMAW-P hybrid welding system; B - hybrid welding torch; $C$ mode of the magnetic field.

However, few studies are implemented in the area of arc characteristics of plasma-GMAW. Plasma-GMAW was first studied by Essers et al. in 1972 and could be achieved in a single torch (Refs. 17-19). The plasma arc plays a role in the keyhole and preheating wire in the plasma-GMAW process. The gas metal arc is significant in gaining stable droplet transfer (Refs. 20, 21). Lower porosity, less welding spatter, and higher efficiency are observed in this method with the complementary advantages of PAW and GMAW (Ref. 22).

Meanwhile, two different welding arc plasmas interact in the workpiece together, which improves welding heat and efficiency compared to a single welding arc plasma (Refs. 23, 24). According to the space position combination structure, the plasma-GMAW method is divided into the coaxial and paraxial plasma-GMAW. At present, the majority of researchers primarily concentrate on coaxial plasma-GMAW, but the structure of the single coaxial hybrid welding torch is complicated, and the plasma current is only focused on low (Ref. 25). Additionally, by comparison, the paraxial plasma-GMAW hybrid has a smaller constricting nozzle, gaining a more concentrated plasma arc (Ref. 26).

Therefore, it is significant and necessary to study and understand the paraxial plasma-GMAW hybrid arc profile and its interaction. Paraxial plasma-pulsed GMAW (plasma-GMAW-P) under the control of the external magnetic field welding method is proposed in this article. Arc profile and the distribution of the temperature field in this method were analyzed by a charge-coupled device (CCD) camera, electrical signals, and an infrared thermal imager, separately. In addition, the plasma-GMAW-P process with different magnetic field currents on medium-thick plates was also carried out to demonstrate the advantage of the external magnetic field.

\section{Experimental System and Procedure}

\section{Experimental System}

The schematic diagram of the experimental welding systems is shown in Fig. 1A, including the PAW power source, GMAW-P power source, magnetic field power source, CCD camera, infrared thermal imaging, current and voltage sensors, data acquisition card, welding robot, and hybrid welding torch. As shown in Fig. 1B, a tandem was realized in the single torch with both the PAW torch and the GMAW torch at a certain angle with the axis of the plasma torch. Field

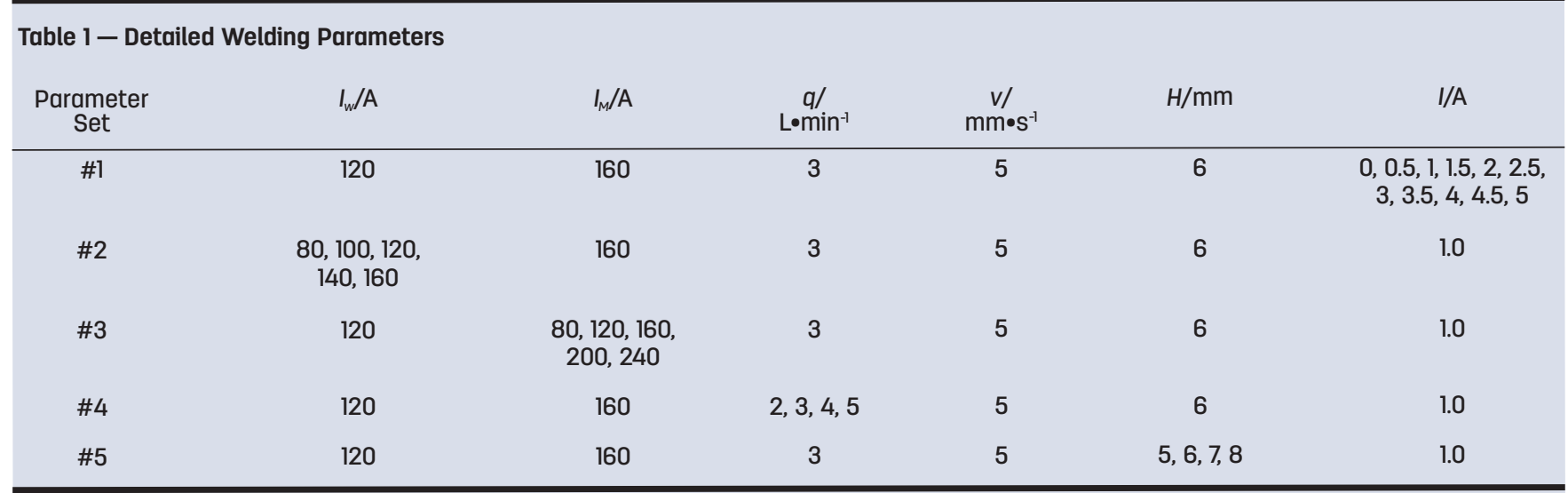



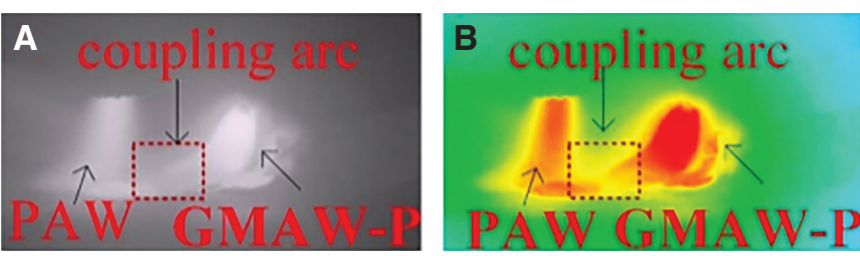

Fig. 2 - Arc profile of plasma-GMAW-P. A - Gray-scale image; $B$ - pseudocolor image.

\begin{tabular}{|c|c|c|c|c|c|}
\hline$I_{M} / \mathrm{A}$ & $I_{p} / A$ & $I_{b} / A$ & $t_{p} / \mathrm{ms}$ & $t_{b} / \mathrm{ms}$ & $f / \mathrm{Hz}$ \\
\hline 80 & 127 & 67 & 3 & 10.5 & 74 \\
\hline 120 & 170 & 95 & 3.5 & 7 & 95 \\
\hline 160 & 200 & 125 & 3 & 3.5 & 153 \\
\hline 200 & 234 & 148 & 3 & 2 & 200 \\
\hline 240 & 281 & 171 & 2.5 & 1.5 & 250 \\
\hline
\end{tabular}

cores were located on both sides of the shielding gas cover and applied as a magnetic conductor by connecting to the field coil. There are 500-turn field coils at every coil frame. The application mode of the magnetic field and the direction of the magnetic field line are depicted in Fig. 1C. The magnetic field lines were generated by the magnetic field power source, then transmitted to the plasma and GMAW-P arc. The direction of the generated magnetic field was vertical to both arcs. Therefore, the plasma and GMAW-P arc were coupled under the function of the magnetic field. The hybrid welding torch and a CCD camera (the Xiris XVC-1000 weld camera, 55 frames/s acquisition rate) were fixed on the robotic manipulator, and the entire welding speed was adjusted by the welding robot directly. The plasma-GMAW-P arc profile in the whole welding process was captured with the $C C D$ camera. The infrared thermal imaging camera (FLIR A315) was fixed directly below the welding workpiece to measure the back temperature of the specimens by surfacing welding, and every welding parameter was measured three times, then the average temperature was taken. The electrical signal acquisition system was composed of a Hall current sensor, a Hall voltage sensor, a National Instruments PCI-6251 data acquisition card, and a computer control system.

The transferred PAW arc was realized by the PAW power source under the direct current straight polarity condition (maximum current of $300 \mathrm{~A}$ ). The GMAW-P arc was burning by the GMAW-P power source under the direct current reverse polarity condition (maximum current of $400 \mathrm{~A}$ ). Therefore, the plasma and GMAW-P arc repelled each other in the actual welding process. The magnetic field was produced by the direct current magnetic field power source (maximum current of $30 \mathrm{~A}$ ).

The medium-thick plates of lower-carbon steel Q235B were used and welded by plasma-GMAW-P utilizing a 3.2-mm tungsten electrode in a 3-mm orifice diameter. The specimen dimensions were $200 \times 100 \times 8 \mathrm{~mm}$, and the specimens' sur-

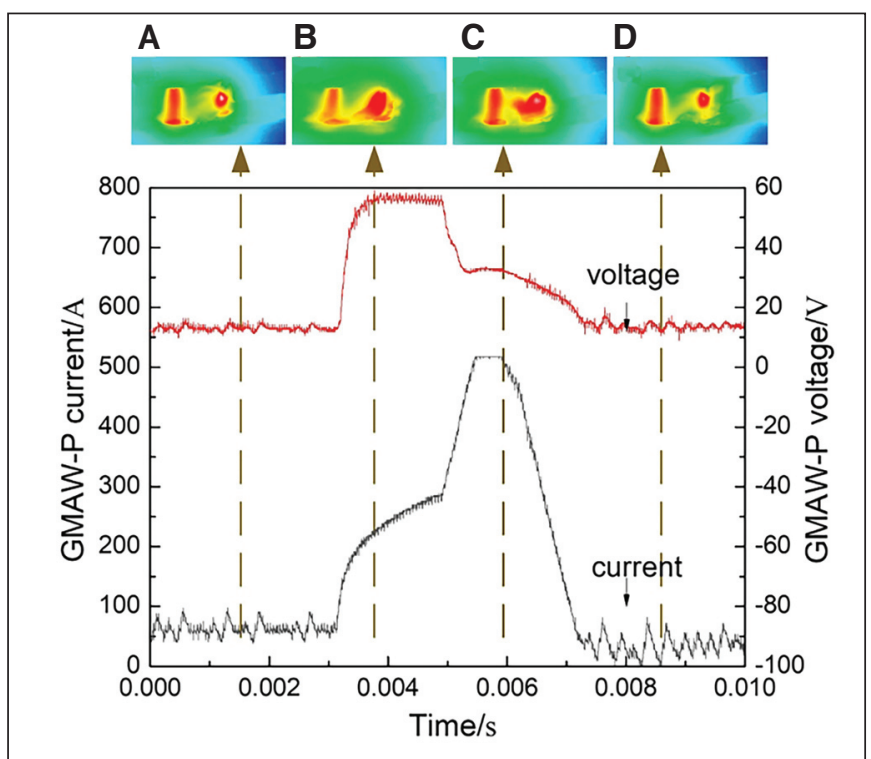

Fig. 3 - The successive images in the one-pulse period of plasma-GMAW-P. A, D - Pulse base phase; $B, C$ - pulse peak phase.

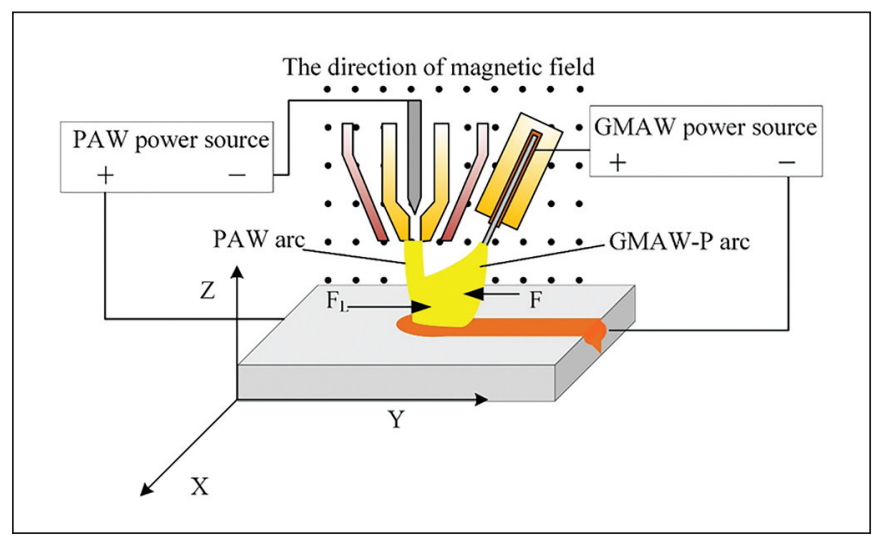

Fig. 4-Schematic diagram of forces on the arc profile.

faces were brushed by a buffing machine and then cleaned with acetone and alcohol in turn. ER50-6 wire with a diameter of $1.2 \mathrm{~mm}$ was chosen as filler metal. Argon (80 vol-\%) and carbon dioxide (20 vol-\%) were used as shielding gas with a flow rate of $12 \mathrm{~L} / \mathrm{min}$. Pure argon (99.99\%) was employed as plasma gas. The other detailed parameters are shown in Table 1 . The distance from the end of PAW to the workpiece is the nozzle height. Plasma welding current, GMAW-P mean current, plasma gas flow, welding speed, nozzle height, and magnetic field current were represented by $I_{w}, I_{M}, q, v, H, I$, respectively. Moreover, Table 2 lists the detailed pulse parameters involving pulse current $\left(I_{p}\right)$, base current $\left(I_{b}\right)$, pulse time $\left(t_{p}\right)$, base time $\left(t_{b}\right)$, and pulse frequency $(f)$.

\section{Experimental Procedure}

In the plasma-GMAW-P hybrid process, the plasma arc and GMAW-P arc were burning and stable, then the magnetic field power source was opened in the welding process. Subsequently, the CCD camera, infrared thermal imaging, and electrical 

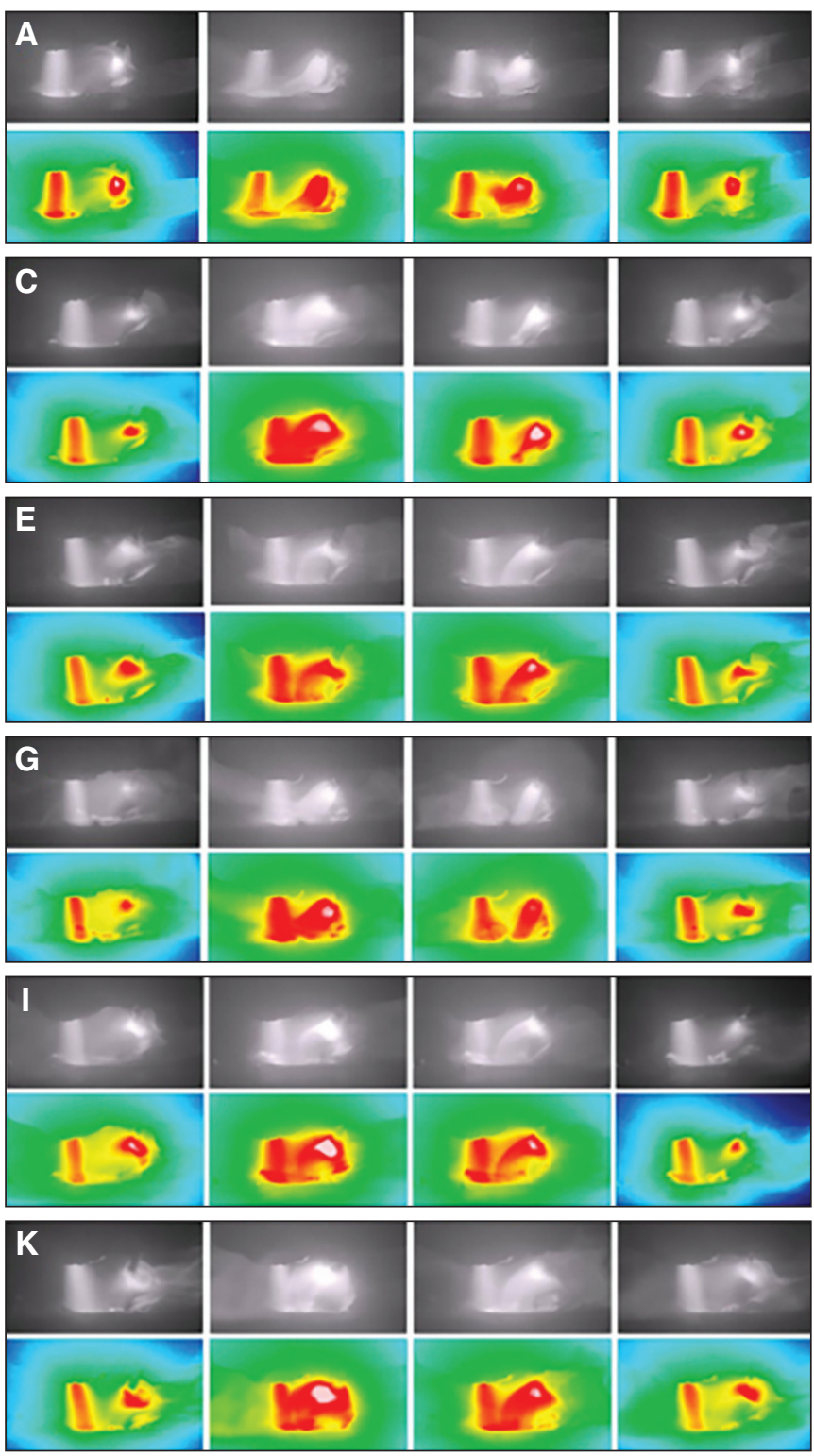

signal acquisition system were also used. The PAW arc was located in front of the welding direction, which formed a keyhole in the workpiece. The GMAW-P arc was in the rear.

All the workpieces were polished to remove the surface oxidation film before welding and then cleaned by alcohol and acetone. All the metallographic specimens, tensile specimens, and bending specimens were cut out from the weld joints by wire cutting after welding. After the metallographic specimens were ground, polished, then etched, the metallographic test was conducted through the Olympus-DSX510 optical microscope. Welding reinforcement and back-side regions of the test specimens and bending specimens were removed by the milling machine. The tensile and bending tests were carried out by an electronic tensile testing machine (CSS-44400) with a travel speed of $1 \mathrm{~mm} / \mathrm{min}$. Apart from the tensile and bending tests, the microhardness of the welding joints was measured via a digital microhardness tester (ArtCAM-400SSI-C) with a load of $2.94 \mathrm{~N}$ and time of $10 \mathrm{~s}$.
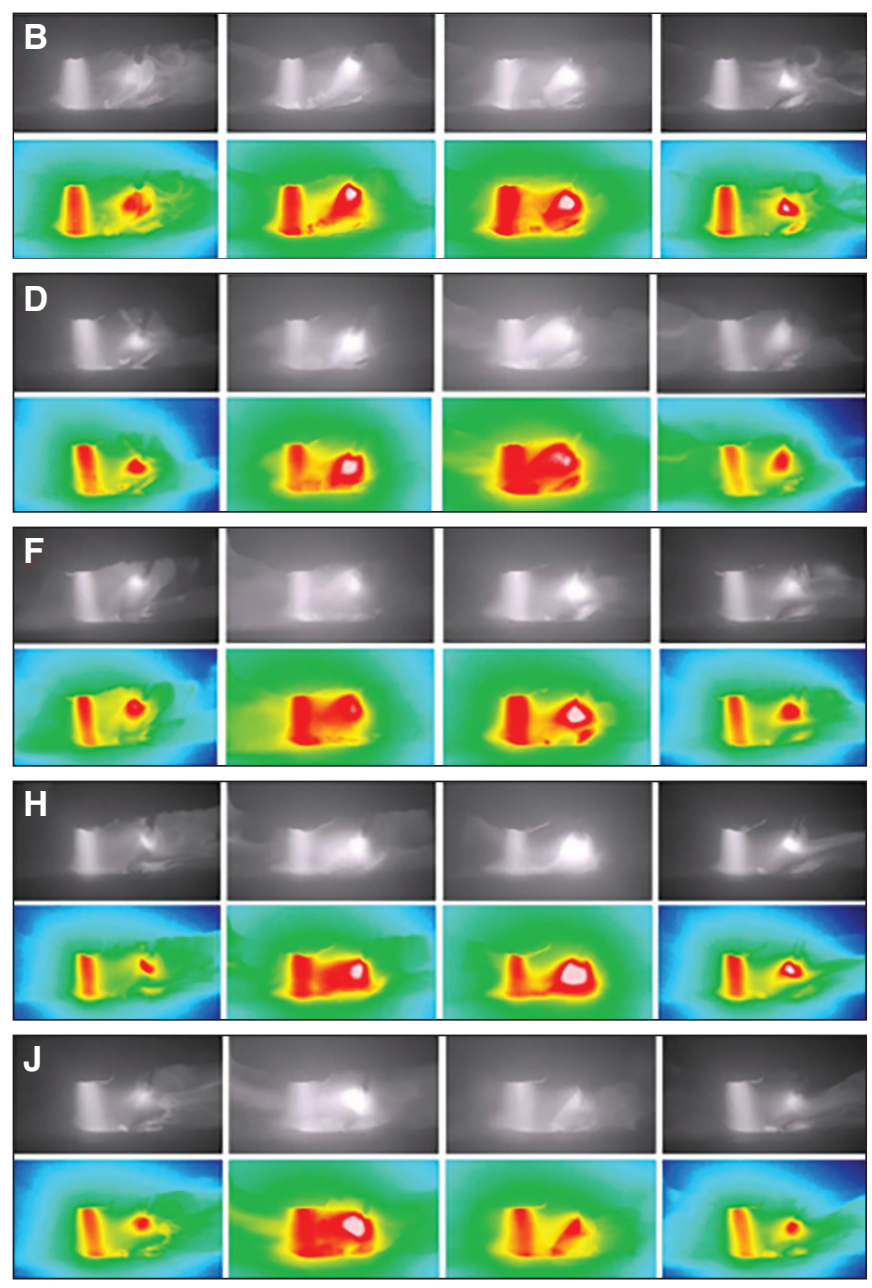

Fig. 5-Schematic diagram of the plasma-GMAW-P arc profile at different magnetic field currents. $A-O A ; B-0.5 \mathrm{~A}$; $C-1 A ; D-1.5 A ; E-2 A ; F-2.5 A, G-3 A ; H-3.5 A ; I-$ $4 A ; J-4.5 A ; K-5 A$.

\section{Results and Discussions}

Pseudocolor processing in Xiris WeldStudio ${ }^{\mathrm{TM} \circledast}{ }^{\mathrm{s}}$ sftware (2.0.3, Xiris Automation, Burlington, Ontario, Canada) could convert the required gray-scale images from the $\mathrm{CCD}$ camera to pseudocolor images to analyze conveniently in Fig. 2. As shown in Fig. 2, the plasma arc was perpendicular to the welding workpiece and the GMAW-P arc was biased to the workpiece because the axes of the two arcs had certain angles. According to the arc profile, the plasma-GMAW-P arc shape could be divided into the following three regions: plasma arc, GMAW-P arc, and coupling arc. The successive images of the arc profile of plasma-GMAW-P without the magnetic field in the one-pulse period were depicted in Fig. 3, according to experimental parameter Set \#1 in Table 1 . The images of the plasma-GMAW-P arc profile in the pulse base phase of the GMAW-P current are shown in Fig. 3A and D. The images of the plasma-GMAW-P arc profile in the pulse peak phase of the GMAW-P current are sketched in Fig. 3B and C.

The main forces acting on the plasma-GMAW-P arc pro- 

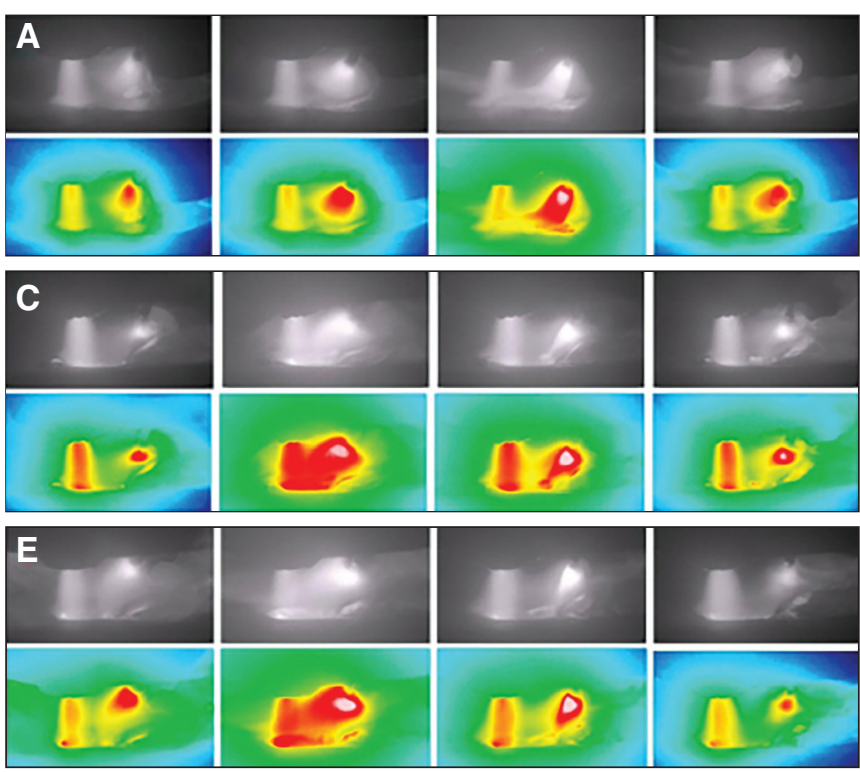

file are Lorentz force, electromagnetic force, repulsive force, surface force, plasma flow force, etc. However, the Lorentz and repulsive force significantly influence the arc profile in the welding process in Fig. 4, which could be calculated by the following formulas, respectively.

(1) Lorentz force, F. Lorentz force is produced in the external magnetic field and can be calculated by Equation 1 as follows:

$$
F=B I L
$$

where $B$ and $I$ are magnetic field intensity and current, respectively.

(2) Repulsive force, $F_{L}$. Repulsive force can be calculated by Equation 2 as follows:

$$
F_{L}=K \frac{I_{1} I_{2}}{L}
$$

where $I_{1}, l$, and $L$ represent the plasma current, GMAW-P current, and the distance between the plasma axis tungsten and wire, respectively. $K$ is the coefficient $(K=\mu / 4 \pi ; \mu$ is dielectric permeability).

\section{The Effect of Welding Parameters on the Plasma-GMAW-P Arc Profile}

To explore the effect of external magnetic field intensity on the plasma-GMAW-P process, the successive images of the hybrid arc profile in the one-pulse period are shown in Fig. 5, according to experimental parameter Set \#1 in Table 1. As shown in Fig. 5, the arc profile was changed at different degrees with the increase of the external magnetic field current.

Figure 5A illustrates the plasma-GMAW-P arc profile without the applied external magnetic field. As seen in Fig. $5 \mathrm{~A}$, when the GMAW-P current was in the pulse base phase, the plasma arc was completely perpendicular to the welding workpiece due to the feature of arc stiffness by itself. However, the plasma arc was inclined forward when the GMAW-
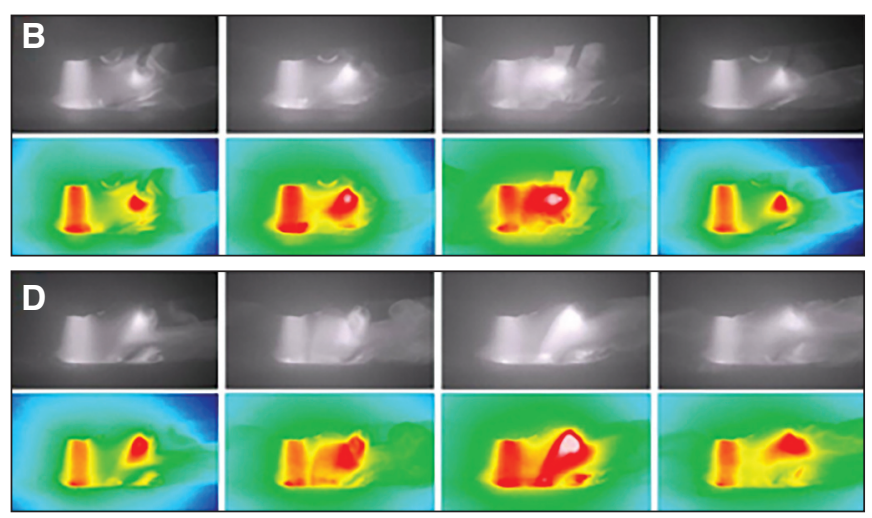

Fig. 6-Schematic diagram of the plasma-GMAW-P arc profile at different plasma welding currents. $A-80 A ; B-100$ $A ; C-120 A ; D-140 A ; E-160 A$.

P current was in the pulse peak phase, which was mainly attributed to the improvement of the repulsive force between the two arcs due to the increase of the GMAW-P current in the pulse peak phase. Moreover, the plasma arc was perpendicular to the welding workpiece again when the GMAW-P current was in the pulse peak phase once again.

The morphology of the hybrid arc changed with the increase of the external magnetic field current. The morphology of the plasma-GMAW-P hybrid arc at different magnetic field currents varying from 0.5 to $5 \mathrm{~A}$ in $0.5 \mathrm{~A}$ increments is illustrated from Fig. 5B to K, respectively. When the magnetic field current didn't exceed $1 \mathrm{~A}$, the plasma arc was always perpendicular to the welding workpiece in the pulse base phase of the GMAW-P current. This may be because the Lorentz and repulsive forces were so much smaller that the plasma arc was still perpendicular to the welding workpiece due to arc stiffness, resulting in the least coupling between the plasma and GMAW-P arc. However, the coupling degree increased when the GMAW-P current was strength-

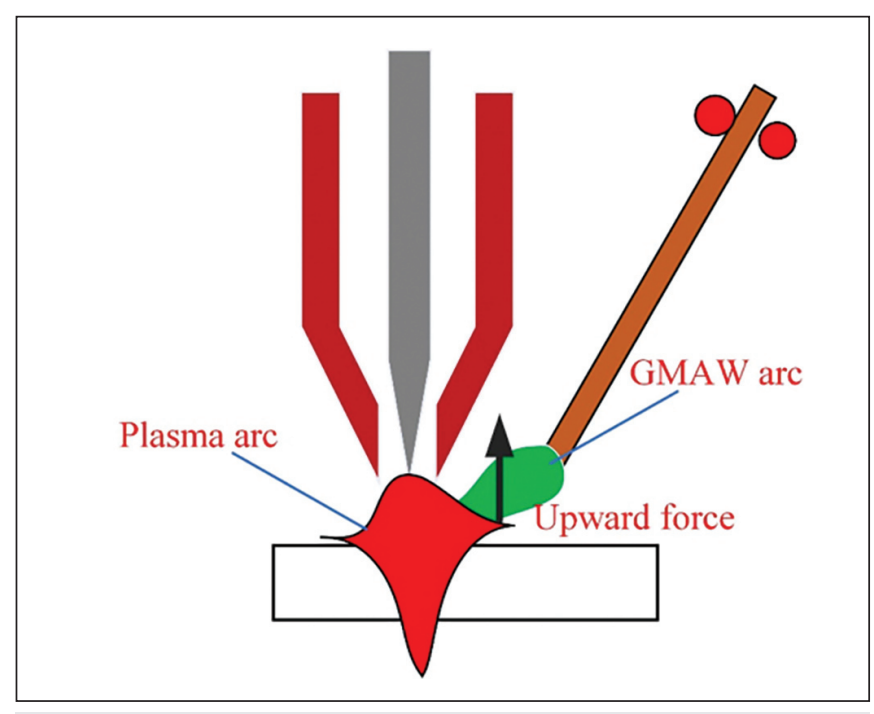

Fig. 7-Schematic diagram of forces in the welding process. 

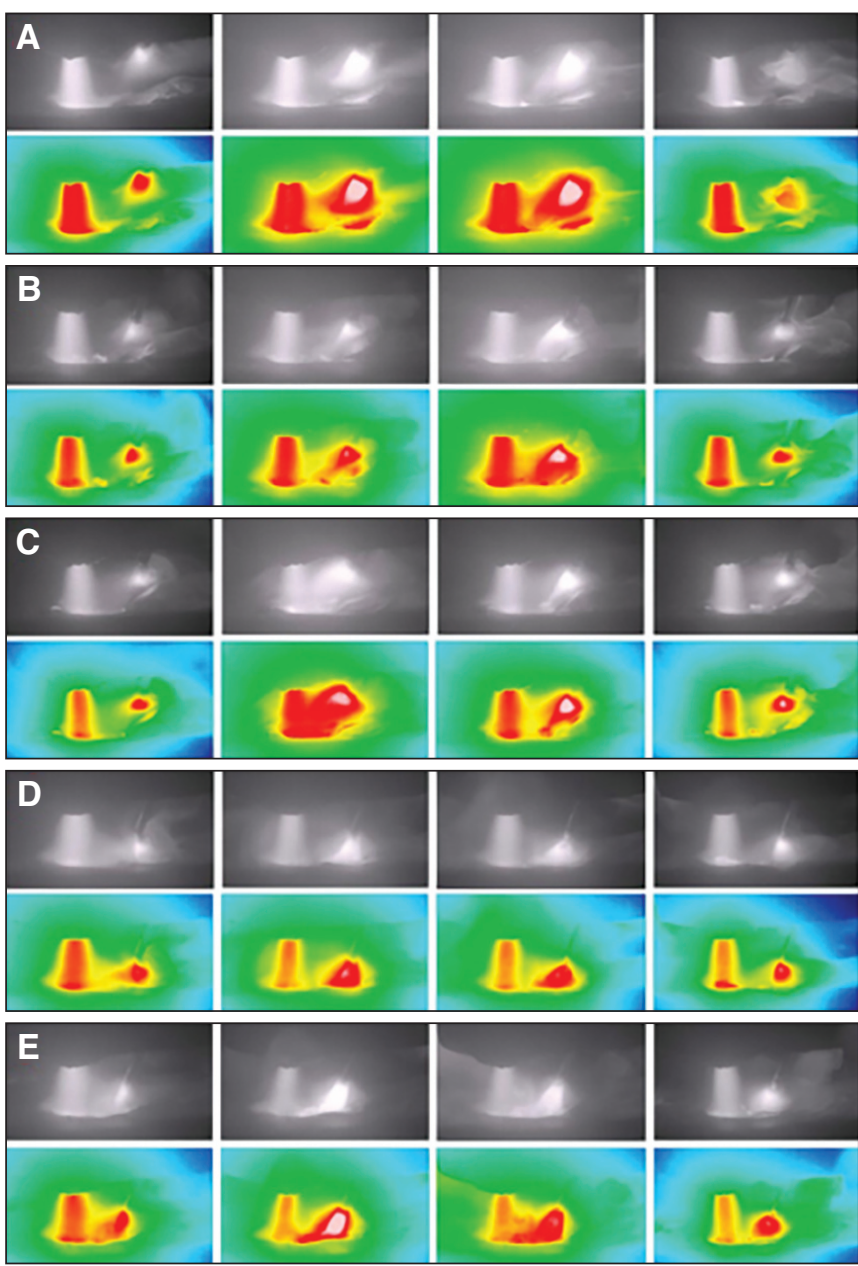

Fig. 8 - Schematic diagram of the plasma-GMAW-P arc profile at different GMAW-P welding currents. $A-80$ A; $B-120$ $A ; C-160$ A; D $-200 A ; E-240$ A.

ened in the pulse peak phase, mainly attributed to the enlarging of the GMAW-P arc column area.

Plasma-GMAW-P arc profiles with magnetic field currents varying from 1.5 to $5 \mathrm{~A}$ are depicted from Fig. 5D to $\mathrm{K}$, which show that the plasma arc was biased to the left side of the GMAW-P arc under the action of Lorentz force in the pulse base phase of the GMAW-P current. When the GMAW-P current remained in the pulse peak phase, the plasma and GMAW-P arc were changed as follows: the magnetic field current increasing from 1.5 to $4 \mathrm{~A}$, the plasma arc was perpendicular to the welding workpiece. This was mainly because the GMAW-P current was increased in the pulse peak stage, which strengthened the repulsive force between the plasma and GMAW-P arc. As a result, the plasma arc moved far away from the GMAW-P arc. Nonetheless, under the combined action of the Lorentz force and the arc stiffness of the plasma arc, the plasma arc was perpendicular to the workpiece. However, when the magnetic field current was 4.5 and $5 \mathrm{~A}$, separately, the plasma arc was still biased to the GMAW-P arc in the pulse peak phase of the GMAW-P current. This was because even if the increase of the GMAW-P current increased the repulsive force, it was still less than the Lorentz force. Besides, compared to the
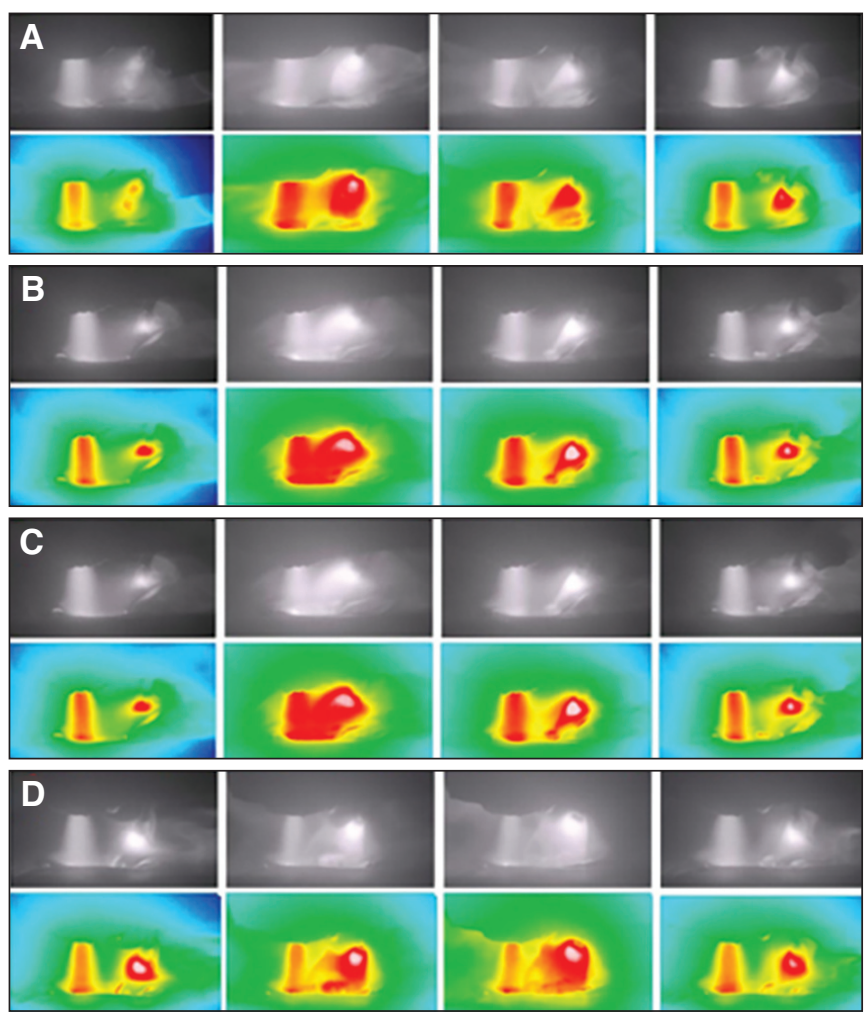

Fig. 9 - Schematic diagram of the plasma-GMAW-P arc profile at different plasma flow rates. $A-2 \mathrm{~L} / \mathrm{min} ; \mathrm{B}-3 \mathrm{~L} / \mathrm{min}$; C $-4 \mathrm{~L} / \mathrm{min} ; \mathrm{D}-5 \mathrm{~L} / \mathrm{min}$.

arc profile at different magnetic field currents, when the magnetic field current was more than $1 \mathrm{~A}$, the coupling degree between the plasma and GMAW-P arc was approximately no longer increased in the pulse peak phase.

\section{The Effect of the Plasma Welding Current on the Plasma-GMAW-P Arc Profile}

To explore the effect of the plasma welding current on the plasma-GMAW-P arc profile, the successive images of the arc profile in the one-pulse period are shown in Fig. 6 according to experimental parameter Set \#2 in Table 1. By comparison, the plasma-GMAW-P arc profile was changed as follows: due to the existence of the external magnetic field, the plasma arc was always perpendicular to the welding workpiece whether the GMAW-P current was in the pulse base phase or peak phase. When the plasma welding current increased from 80 to $120 \mathrm{~A}$, the plasma arc column and diffusion angle increased, which increased the coupling degree of the hybrid arc. However, when the plasma welding current was increased from 140 to $160 \mathrm{~A}$, the coupling degree of the hybrid arc weakened and the coupling position between the plasma and the GMAW-P arc improved, which may be attributed to the increase of the plasma arc column and the diffusion angle. Meanwhile, a partial plasma arc was located below the GMAW-P arc, which produced the upward force on the GMAW-P arc in Fig. 7. Therefore, the coupling position of the hybrid arc improved. However, the coupling degree weakened with the increase of the repulsive force. 


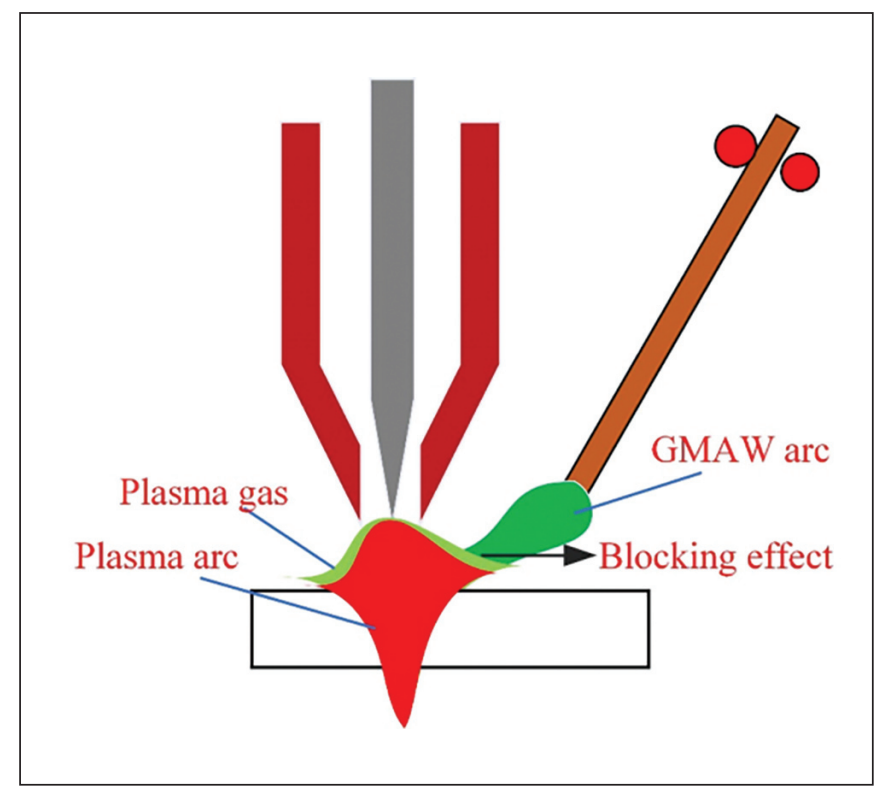

Fig. 10 - Schematic diagram of the increase of plasma gas.

\section{The Effect of the GMAW-P Current on the Plasma-GMAW-P Arc Profile}

To explore the effect of the GMAW-P current on the plasma-GMAW-P arc profile, the successive images of the arc profile in the one-pulse period are shown in Fig. 8, according to experimental parameter Set \#3 in Table 1. When the GMAW-P current was in the pulse base phase, the plasma arc was still perpendicular to the workpiece even if the GMAW-P current was increased. This indicated that the increased repulsive force was less than the Lorentz force. Besides, the plasma arc also had the feature of arc stiffness, and the hybrid arc profile was also changed in the pulse peak phase of the GMAW-P current. When the GMAW-P current was less than $160 \mathrm{~A}$, the coupling degree of the hybrid arc was increased with the strengthening of the GMAW-P current. Whereas, the plasma arc was still perpendicular to the workpiece, which was similar to the condition in the pulse base phase. When the GMAW-P current was more than 160 A, the coupling degree of the hybrid arc decreased as the GMAW-P current increased. This was because the repulsive force grew due to the increase of the GMAW-P current.

\section{The Effect of Plasma Gas Flow on the Plasma- GMAW-P Arc Profile}

Figure 9 depicts the plasma-GMAW-P arc profile at different plasma gas flows, according to experimental parameter Set \#4 in Table 1. As seen in Fig. 9, when the GMAW-P current was in the pulse base phase, the plasma arc was perpendicular to the welding workpiece by Lorentz force under the function of the external magnetic field. However, when the GMAW-P current was in the pulse peak phase, the plasma arc was changed as follows: Firstly, as shown in Fig. 9A, when the plasma flow rate was $2 \mathrm{~L} / \mathrm{min}$, the plasma arc tilted forward in the pulse peak phase of the GMAW-P current.
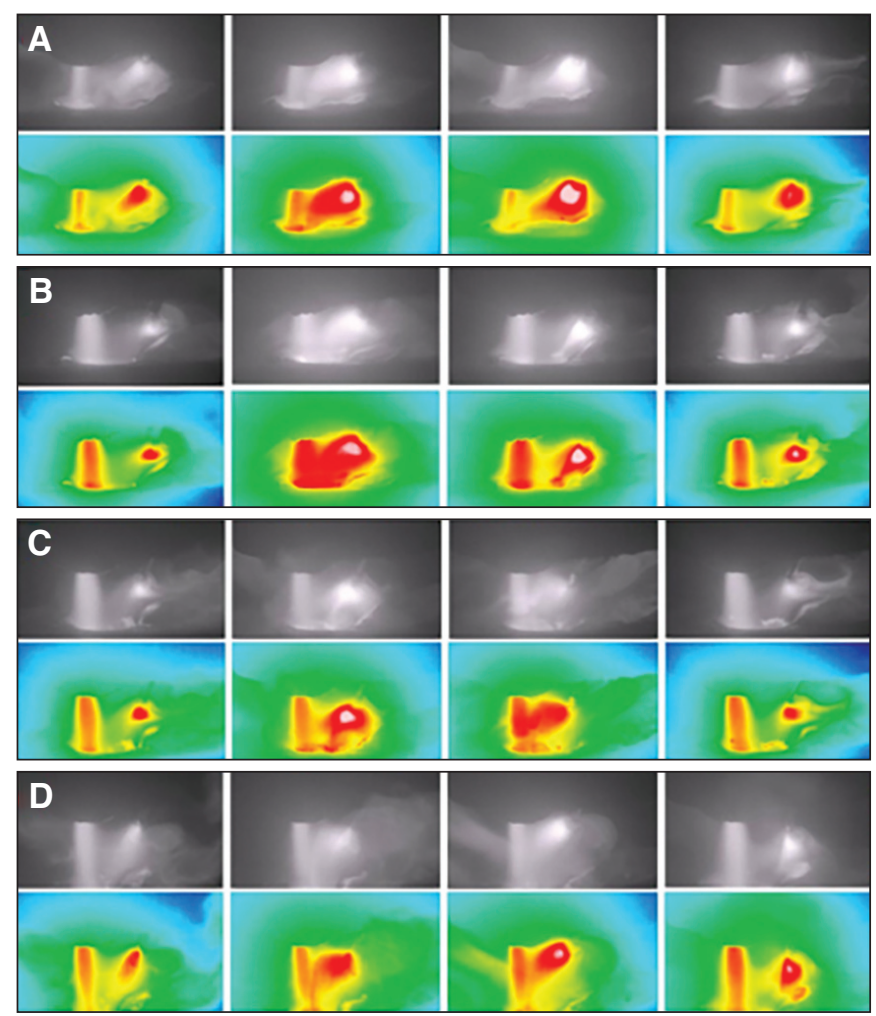

Fig. 11 - Schematic diagram of the plasma-GMAW-P arc profile at different nozzle heights. $A-5 \mathrm{~mm} ; \mathrm{B}-6 \mathrm{~mm} ; \mathrm{C}-7$ $\mathrm{mm} ; \mathrm{D}-8 \mathrm{~mm}$.

This was mainly because the Lorentz force was less than the arc repulsion force. Secondly, as shown in Fig. 9B, the coupling degree between the plasma and GMAW-P arc was the largest when the flow rate of plasma gas raised to $3 \mathrm{~L} / \mathrm{min}$. However, the coupling degree between the GMAW-P and plasma arc decreased when the flow rate of plasma gas was 4 and $5 \mathrm{~L} / \mathrm{min}$ as shown in Fig. $9 \mathrm{C}$ and $\mathrm{D}$, respectively. The main reason was with the increase of the plasma gas flow rate, the plasma gas outside the plasma arc column was signally increased in Fig. 10, then the blocking effect on the GMAW-P arc was generated. As a result, the coupling degree between the plasma and GMAW-P arc was reduced.

\section{The Effect of Nozzle Height on the Plasma- GMAW-P Arc Profile}

Figure 11 depicts the plasma-GMAW-P arc profile at different nozzle heights, according to experiment parameter Set \#5 in Table 1. When the GMAW-P current was in the pulse base phase, the hybrid arc profile was changed as follows: when the nozzle height was 5 and $6 \mathrm{~mm}$, the plasma arc was perpendicular to the welding workpiece. However, when the nozzle height increased to 7 and $8 \mathrm{~mm}$, the plasma arc was inclined to the side of the GMAW-P arc. There were two reasons for this: one was the action of Lorentz force in the external magnetic field, and the other was the increase of arc length decreased the stiffness of the plasma arc.

Therefore, the deviation degree of the plasma arc increased with the increase of nozzle height. Besides, the plasma and 

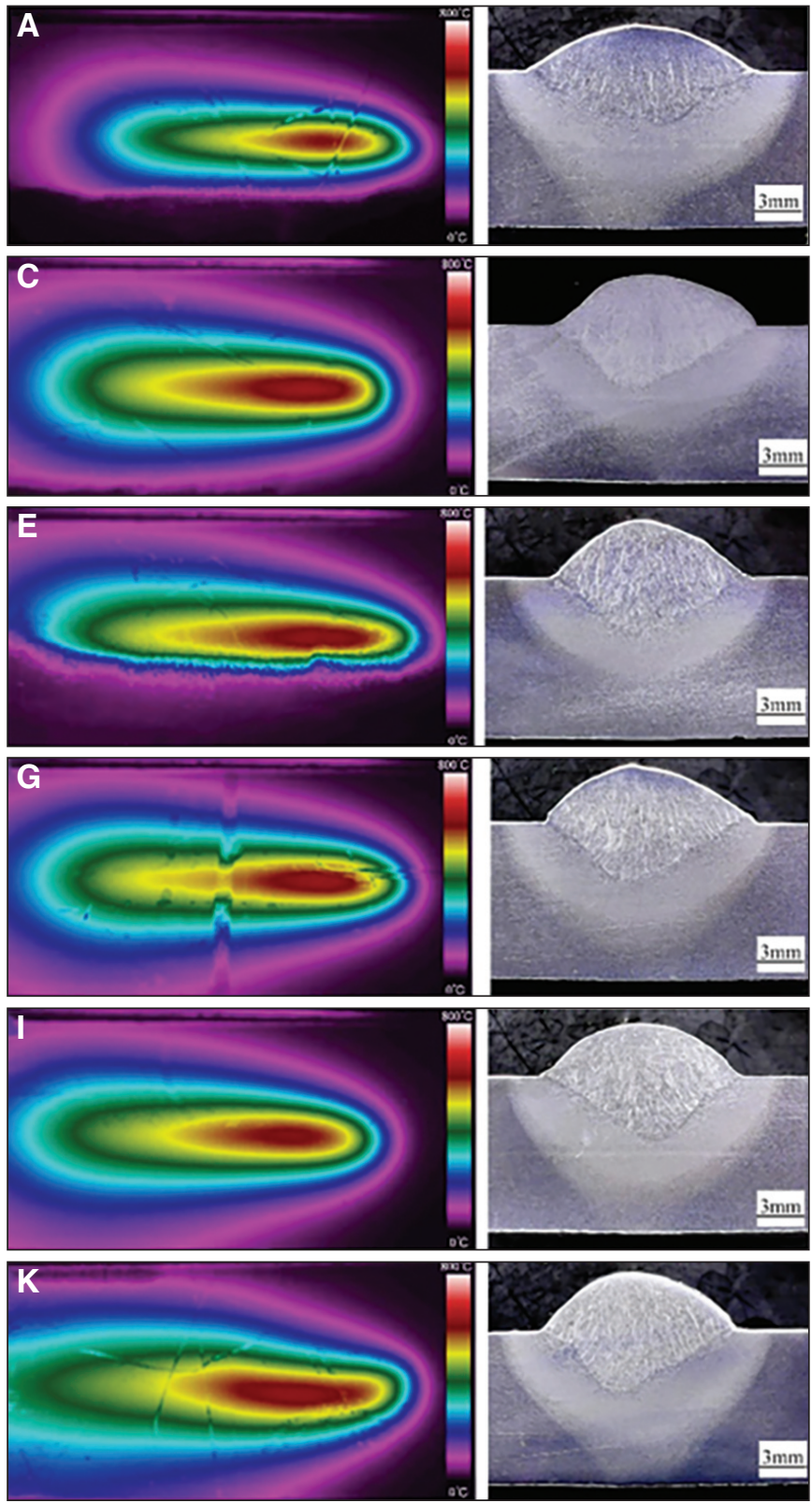

GMAW-P arc were coupled when the GMAW-P current was in the pulse peak phase. The coupling degree between the plasma and GMAW-P arc was the largest when the nozzle height was $6 \mathrm{~mm}$. The coupling position of the two arcs increased with the increase of nozzle height, which was attributed to the increase of the plasma arc column and the diffusion angle as a result of raising the nozzle height. Part of the plasma arc was located at the bottom of the GMAW-P arc in Fig. 7, which produced an upward thrust on the GMAW-P arc, causing the increase of the coupling position.

\section{Analysis of Temperature Field Based on Infrared Thermal Imaging Technology}

Figure 12 illustrates the back-surface temperature and cross-section morphology of surfacing specimens, both taken at the same time, under different magnetic field currents. Be-
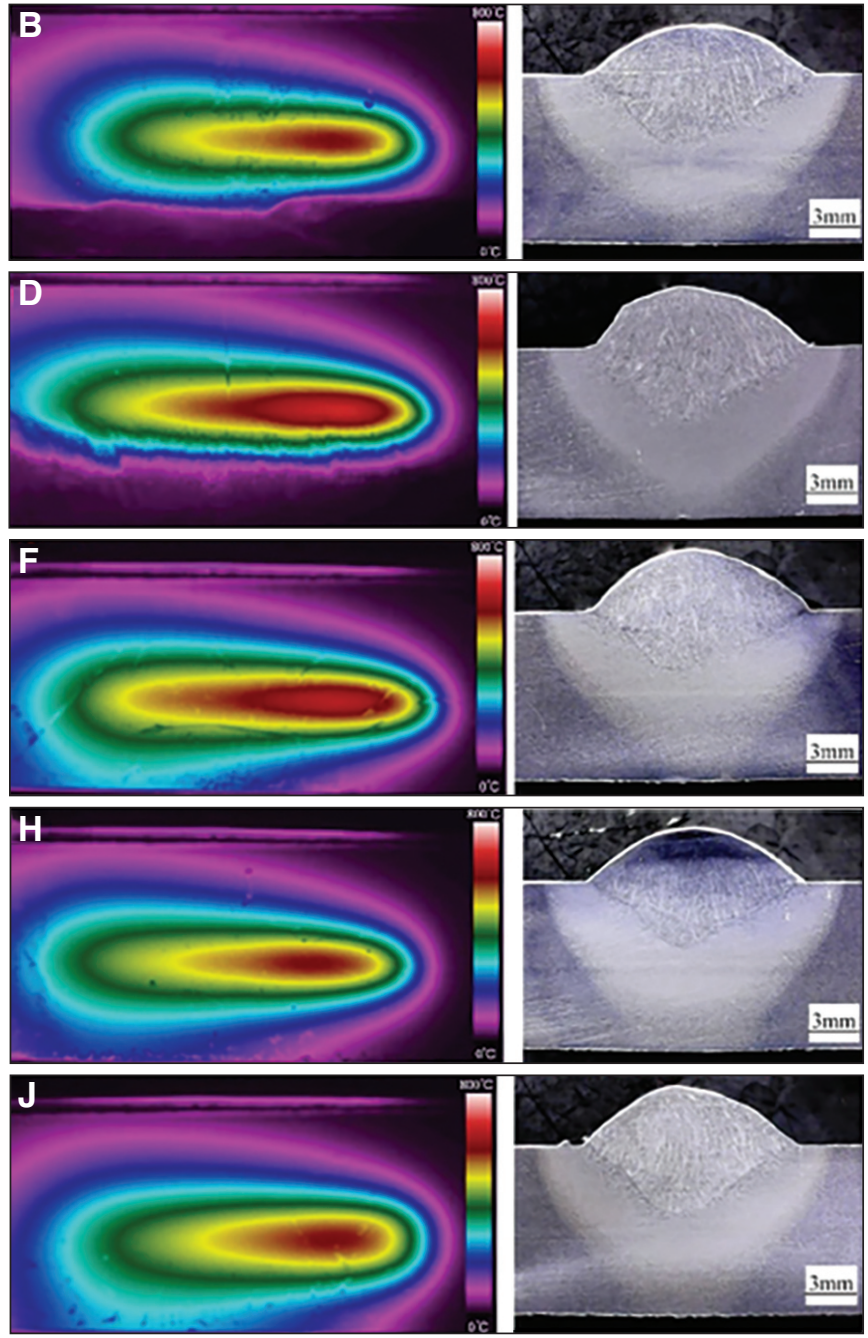

Fig. 12 - Back-surface temperature field distribution of welded specimens and cross-section morphology under different magnetic field currents. $A-O A ; B-0.5 A ; C-1 A ; D$ $-1.5 \mathrm{~A} ; E-2 \mathrm{~A} ; \mathrm{F}-2.5 \mathrm{~A} ; \mathrm{G}-3 \mathrm{~A} ; \mathrm{H}-3.5 \mathrm{~A} ; \mathrm{I}-4 \mathrm{~A} ; \mathrm{J}-$ $4.5 A ; K-5 A$.

cause the welding workpiece had a certain distance from the infrared thermal imaging, the back-surface temperature of all measured workpieces was between $0^{\circ}$ and $800^{\circ} \mathrm{C}$.

According to the change of the temperature field, the maximum and minimum temperatures were extracted. The correlative curves of the joint penetration at the same time as the maximum temperature of the back surface, as well as the average temperature of the back surface at different magnetic field currents are illustrated in Fig. 13A and B, respectively. The maximum temperature varied mainly from $580^{\circ}$ to $700^{\circ} \mathrm{C}$. When the magnetic field current was $1.5 \mathrm{~A}$, the maximum temperature reached $691^{\circ} \mathrm{C}$, increased by $6.7 \%$ compared to the maximum temperature without the magnetic field. Besides, the joint penetration was obviously improved. The curve between the maximum temperature of the back-surface sample and joint penetration at the same magnetic field current had no obvious change. Figure 13B sketches the relevant curve of joint penetration and the av- 

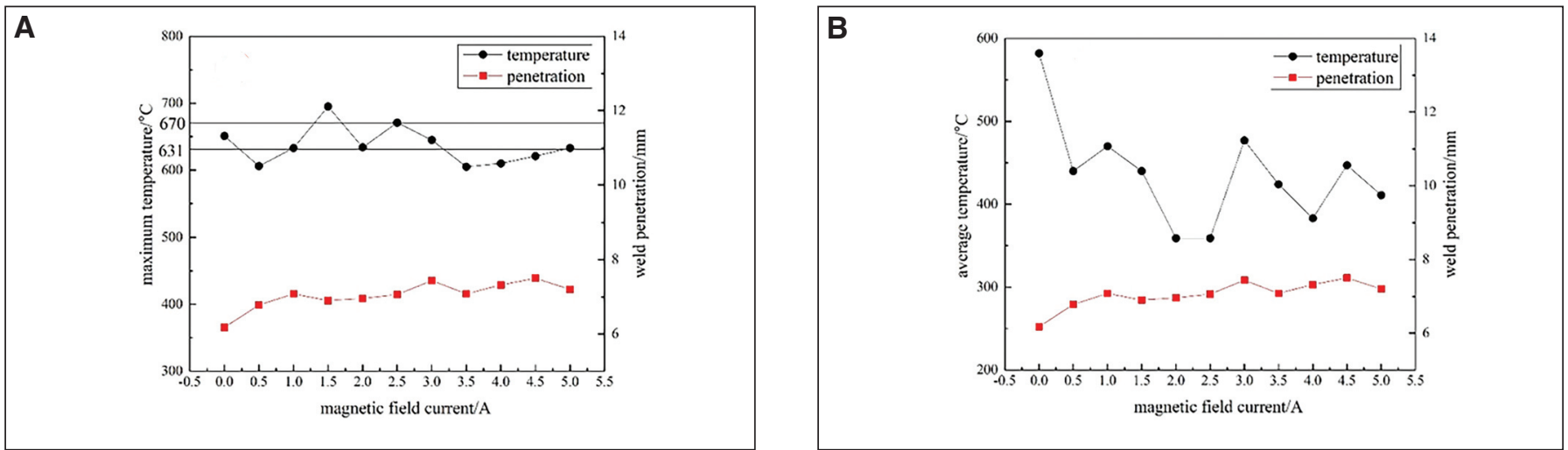

Fig. 13 - The correlative curves of joint penetration and the back-surface temperature at different magnetic field currents. A The correlative curve of the joint penetration and the maximum temperature; $B$ - the correlative curve of the penetration and the average temperature.

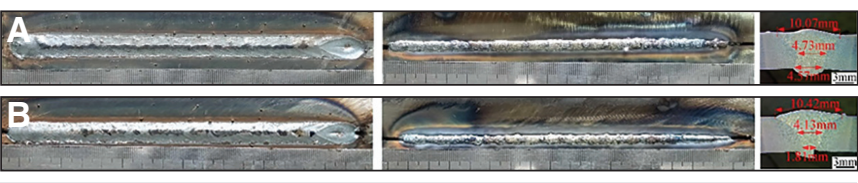

Fig. 14 - Macro morphology and cross sections of welded joints at different magnetic field currents. $A-0 A ; B-2 A$.

erage temperature of the back surface at the different magnetic field currents, which was considered as approximately the inverse proportion between the average temperature and joint penetration. It is possible the reason was that the hybrid arc shrunk and coupled under the effect of the magnetic field, causing the more concentrated arc heat source. Therefore, the heat going into the incoming workpiece increased, urging the increased joint penetration and the decreased average temperature.

To verify the advantage of the external magnetic field further, a butt joint was welded with the magnetic field currents of 0 and $2 \mathrm{~A}$. The other detailed welding parameters were fixed

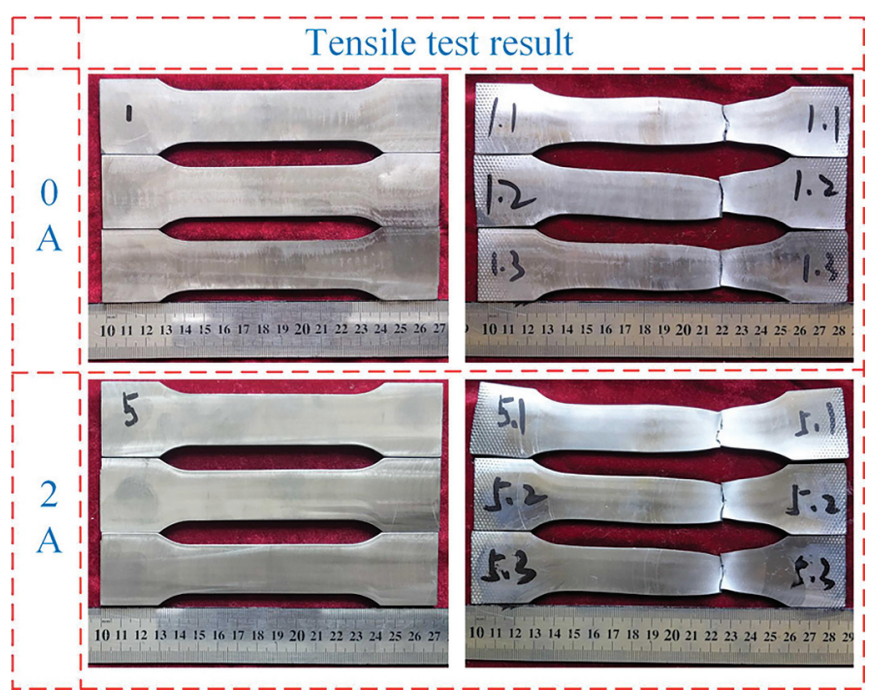

Fig. $15-$ Schematic of broken specimens after tensile test at different magnetic fields.

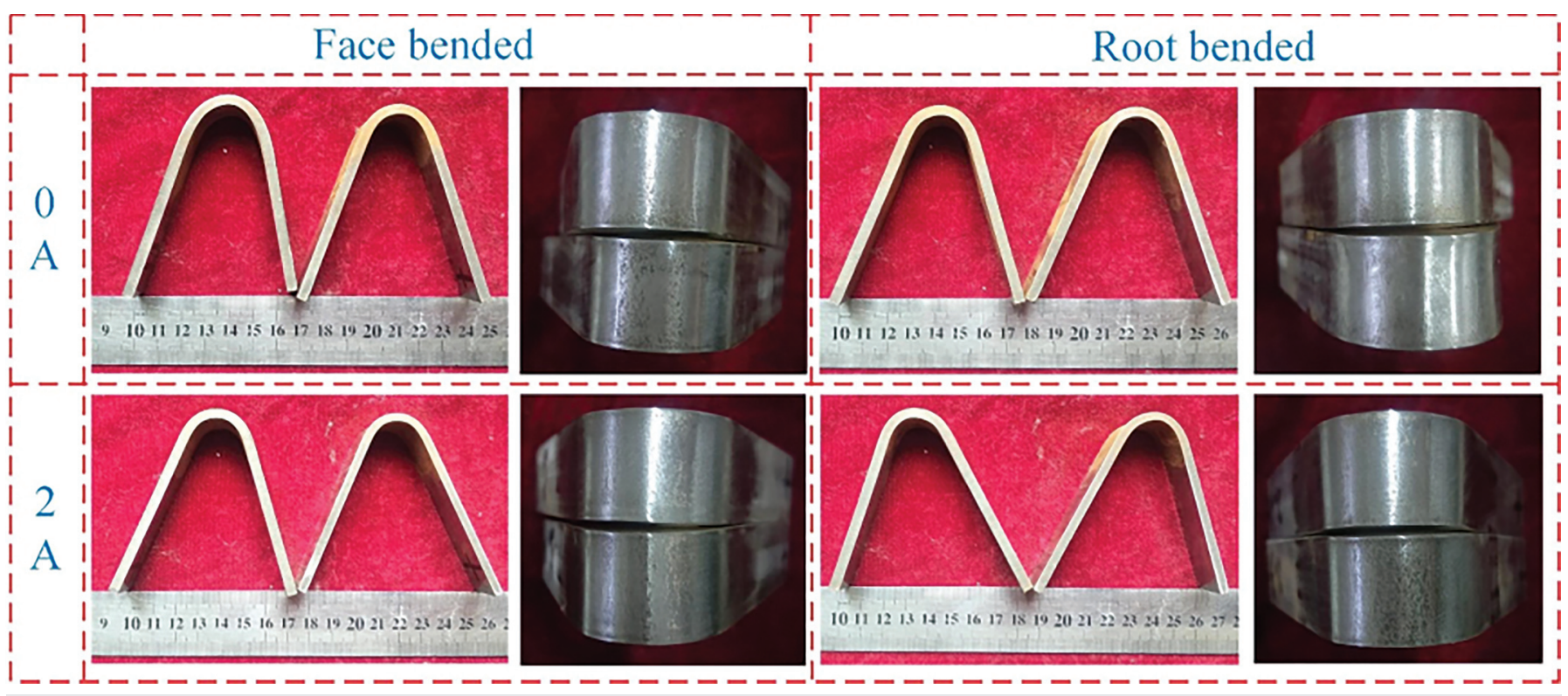

Fig. 16 - Bended butt joint specimens at different magnetic field currents. 


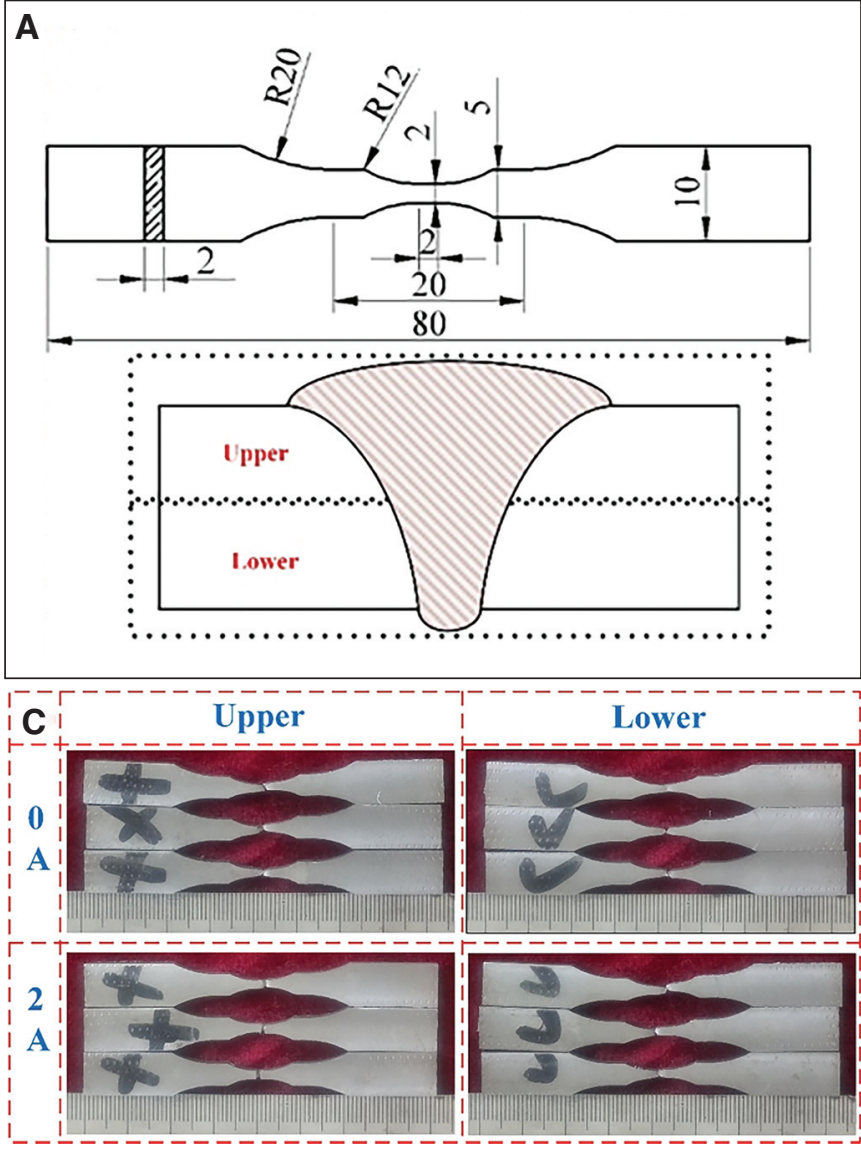

Fig. $17-$ The tensile test results of the fusion zone. ASchematic diagram of tensile samples and the sampling locations; $B$ - the tensile strength at different welding currents; $\mathrm{C}$ - the macroscopic picture of fractured tensile samples.

on experimental parameter Set \#1 in Table 1. Weld formation, microstructure, and mechanical properties tests of butt joints at the two currents were compared.

\section{Variation in Weld Appearance}

Figure 14 depicts the surface appearance and cross sections of welded joints at different magnetic field currents. Compared with the front side and back side of the weld joints, it was found that smooth and uniform surfaces were acquired in two ways. The clear fish scale appeared obviously in the weld surface without the magnetic field. Meanwhile, the weld width of the upper part of the welded joints was increased from 10.07 to $10.42 \mathrm{~mm}$ with the magnetic field current of $2 \mathrm{~A}$, increasing the ratio of depth to width. However, due to the effect of the coupling arc, the weld width of the middle and the lower part of the welded joints decreased from $4.73 / 4.57$ to $4.13 \mathrm{~mm} / 1.81 \mathrm{~mm}$, respectively, which increased the ratio of depth to width of the welded joints.

\section{Variation in Mechanical Properties}

\section{Tensile and Bending Tests}

Figure 15 shows the tensile test results at different magnetic field currents. It was found that all the broken speci-
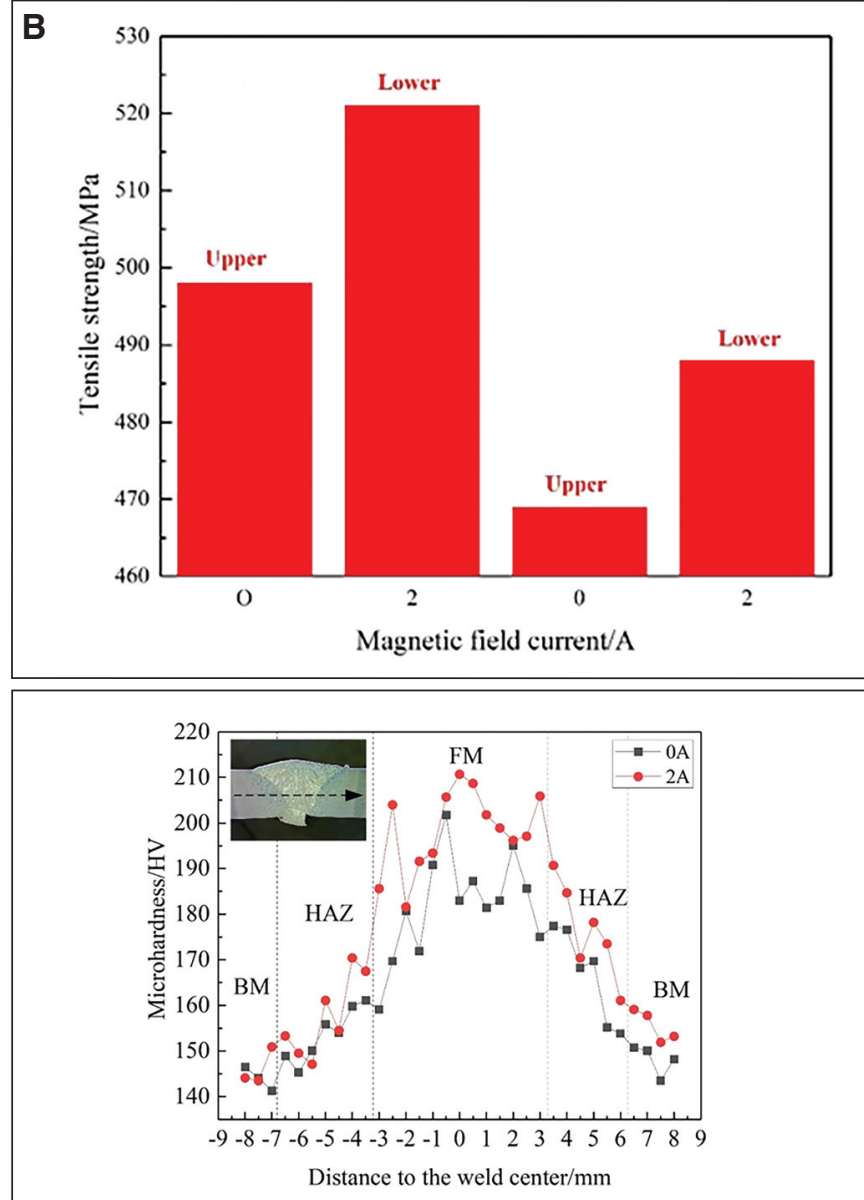

Fig. 18 - Microhardness profile on cross sections of weld joints at different magnetic field currents.

mens were fractured at the base metal in two ways. Figure 16 illustrates the macro morphology of the welding joints at different magnetic fields after the bending test. The bending degrees of two joints were approximately similar.

\section{Tensile Test on Fusion Zone of Joints}

Compared to the tensile and bending tests, the results of all the tensile and bending specimens at different magnetic field currents were similar. Therefore, to verify the advantages of the magnetic field, some novel test specimens were obtained in Fig. 17A, which could determine the strength of the fusion zone. The tensile test results of the fusion zone are sketched in Fig. 17B and C. The result showed that when the magnetic field current was $2 \mathrm{~A}$, tensile strength on the upper and lower part of the tensile samples were 521 and $488 \mathrm{MPa}$, respectively, which were $4.6 \%$ and $3.2 \%$ higher than those without magnetic field.

\section{Hardness Profile}

The microhardness of welded joints at different magnetic field currents is depicted in Fig. 18. As shown in Fig. 18, the black arrow shows the direction and location of hardness measurements. By comparison, the microhardness of weld- 


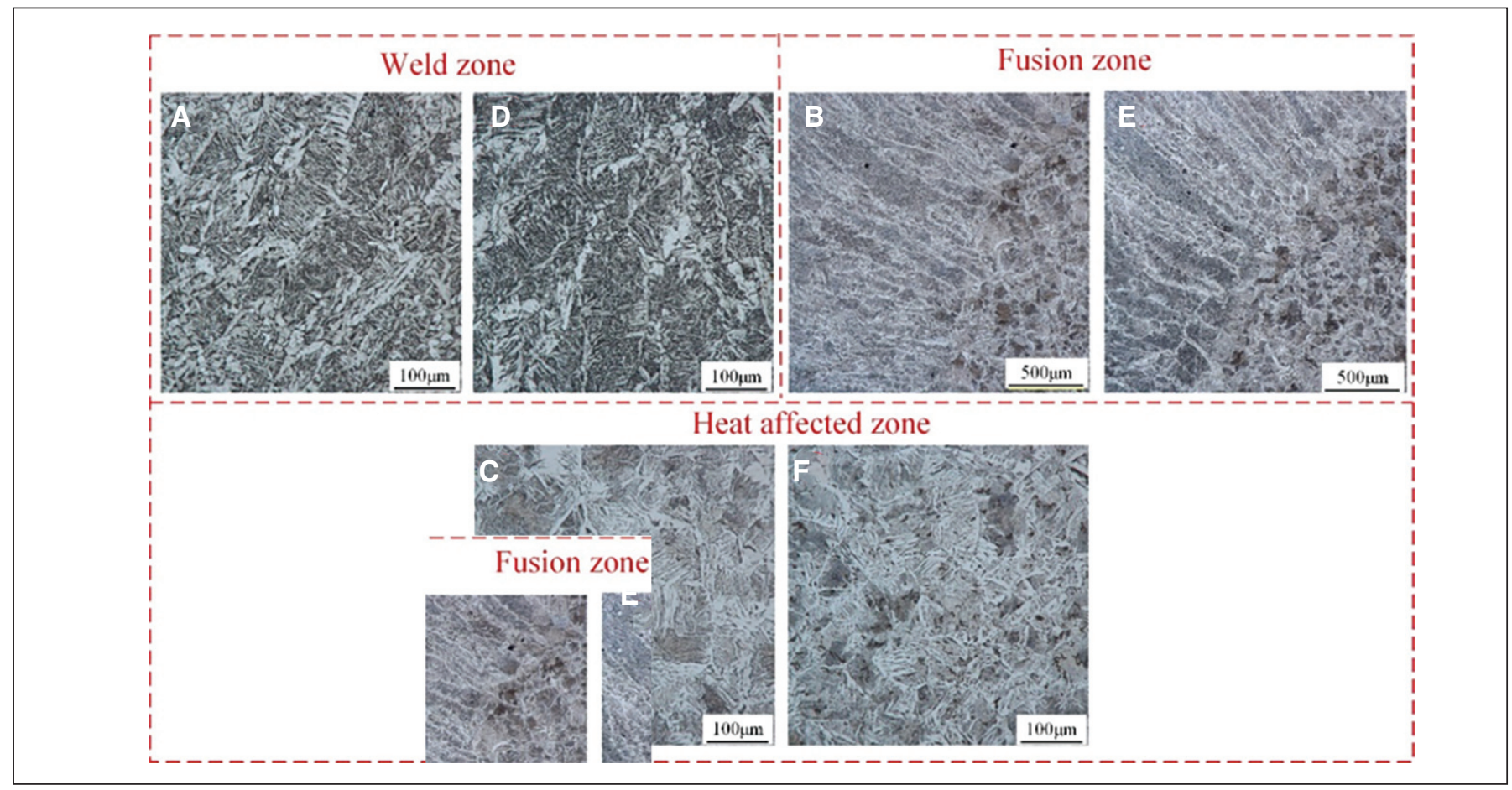

Fig. 19 - Optical microstructures of welded joints at different magnetic field currents. A-C $-0 A ; D-F-2 A$.

ed joints improved with the application of the external magnetic field.

\section{Microstructure}

Optical microstructures and compositions directly determined the performance of welded joints (Ref. 27). Figure 19 depicts the optical microstructure of welded joints at different magnetic field currents, including the weld zone, fusion zone, and heat-affected zone (HAZ). As seen in Fig. 19, compared to the weld zone at different magnetic fields, the acicular ferrite slightly increased with the increase of magnetic field intensity. The size of the epitaxial growth increased, and the grain size in the HAZ decreased when the magnetic field current reached $2 \mathrm{~A}$, which was possible due to the arc coupling stirring the weld pool.

\section{Conclusion}

The conclusions were as follows:

1. There was an obvious distinction in the plasma-GMAW$\mathrm{P}$ arc profile at different welding parameters. It was found that the plasma and GMAW-P arcs were coupled by the Lorentz force, and the coupling degree of the two arcs increased with the strengthening of the magnetic field current. When the magnetic field current was greater than $1 \mathrm{~A}$, the arc profile was changed slightly with the increase of the magnetic field intensity. Besides, fixed on the magnetic field current of $1 \mathrm{~A}$, the coupling degree first increased and then decreased with the increase of the plasma current, GMAW-P current, plasma gas flow rate, and nozzle height, respectively.

2. The correlative curves between the back-surface temperature and joint penetration illustrated that the maximum temperature had no obvious effect on joint penetration.
However, the average temperature had an inverse effect on joint penetration at different magnetic field currents. A possible reason was that the heat of the coupled arc was more concentrated under the action of Lorentz force. Therefore, the heat transferred into the workpiece was increased, causing the increase of the penetration and the decrease of the temperature on the back of the surfacing specimen.

3. Compared with the average plasma-GMAW-P, the ratio of depth to width of welded joints increased with the increase of magnetic field current. Under the action of the external magnetic field current, all tensile specimens were fractured at the base metal and the bending degree of two joints was similar. The weld fusion zone joint tensile test result showed that when the magnetic field current was $2 \mathrm{~A}$, tensile strength on the part and the lower part of the tensile samples were 521 and $488 \mathrm{MPa}$, respectively, which were $4.6 \%$ and 3.2\% higher than those without magnetic field. The hardness test showed that the hardness of the weld zone was higher than that without the magnetic field. The reason was that more acicular ferrites in the weld zone were generated under the magnetic field.

\section{Acknowledgment}

The work was financially supported by major scientific and technological innovation projects in Shandong Province (2019JZZY010366) and Young Taishan Scholars Program of Shandong Province (tsqn20161062).

\section{References}

1. Auwal, S. T., Ramesh, S., Yusof, F., and Manladan, S. M. 2018. A review on laser beam welding of copper alloys. International Jour- 
nal of Advanced Manufacturing Technology 96(1-4): 475-490. DOI: 10.1007/s00170-017-1566-5

2. Węglowski, M. S., Błacha, S., and Phillips, A. 2016. Electron beam welding - Techniques and trends - Review. Vacuum 130: 72 92. DOI: 10.1016/j.vacuum.2016.05.004

3. Li, Z. Y., Srivatsan, T. S., Li, Y., and Zhang, W. Z. 2013. Coupling of laser with plasma arc to facilitate hybrid welding of metallic materials: A review. Journal of Materials Engineering and Performance 22(2): 384-395. DOI: 10.1007/s11665-012-0280-6

4. Wang, G., Zhang, K. F., Wen, B. H., Wu, D. Z., and Wang, C. W. 2007. Superplastic bulging capability of Ti-6Al-4V butt-welded plate by high energy beam welding. Materials Science Forum 551552: 411-416. DOI: 10.4028/www.scientific.net/msf.551-552.411

5. Liu, L. M., and Jiang, J. B. 2008. Keyhole mode variable polarity plasma arc weld bonding of $\mathrm{Mg}$ alloy. Materials Research Innovations 12(3): 147-150. DOI: 10.1179/143307508x333695

6. Taban, E., and Kaluc, E. 2011. Welding behaviour of duplex and superduplex stainless steels using laser and plasma arc welding processes. Welding in the World 55(7-8): 48-57. DOI: 10.1007/ bf03321307

7. Chinakhov, D. A., Solodsky, S. A., Rodionov, P. V., and Sydorets, V. N. 2018. Energy parameters of weld formation process in MIG-MAG welding. Materials Science Forum 927: 99-105. DOI: 10.4028/www.scientific.net/msf.927.99

8. Xiong, J., Lei, Y. Y., Hui, C., and Zhang, G. J. 2017. Fabrication of inclined thin-walled parts in multi-layer single-pass GMAW-based additive manufacturing with flat position deposition. Journal of Materials Processing Technology 240: 397-403. DOI: 10.1016/j.jmatprotec.2016.10.019

9. Lee, H. K., Park, S. H., and Kang, C. Y. 2015. Effect of plasma current on surface defects of plasma-MIG welding in cryogenic aluminum alloys. Journal of Materials Processing Technology 223: 203-215. DOI: 10.1016/j.jmatprotec.2015.04.008

10. Yang, T., Gao, H. M., Zhang, S. H., Shi, J. W., and Wu, L. 2013. The study on plasma-MIG hybrid arc behaviour and droplet transfer for mild steel welding. Reviews on Advanced Materials Science 33(5): 459-464.

11. Zhang, C. Y., Ma, G. H., Nie, J., and Ye, J. 2015. Numerical simulation of AZ31B magnesium alloy in DE-GMAW welding process. The International Journal of Advanced Manufacturing Technology 78(5-8): 1259-1264. DOI: 10.1007/s00170-014-6703-9

12. Yang, D. Q., He, C. J., and Zhang, G. J. 2016. Forming characteristics of thin-wall steel parts by double electrode GMAW based additive manufacturing. Journal of Materials Processing Technology 227: 153-160. DOI: 10.1016/j.jmatprotec.2015.08.021

13. Schnick, M., Wilhelm, G., Lohse, M., Füssel, U., and Murphy, A. B. 2011. Three-dimensional modelling of arc behaviour and gas shield quality in tandem gas-metal arc welding using anti-phase pulse synchronization. Journal of Physics D: Applied Physics 44(18): 185205. DOI: 10.1088/0022-3727/44/18/185205

14. Sen, M., Mukherjee, M., Singh, S. K., and Pal, T. K. 2018. Effect of double-pulsed gas metal arc welding (DP-GMAW) process variables on microstructural constituents and hardness of low carbon steel weld deposits. Journal of Manufacturing Processes 31: 424-439. DOI: 10.1016/j.jmapro.2017.12.003

15. Liu, A. H., Tang, X. H., and Lu, F. G. 2013. Arc profile characteristics of Al alloy in double-pulsed GMAW. The International Journal of Advanced Manufacturing Technology 65(1-4): 1-7. DOI: 10.1007/s00170-012-4141-0

16. Wu, K. Y., Xie, P. M., Liu, Z., Zeng, M., and Liang, Z. Y. 2020. Investigation of double arc interaction mechanism and quantita- tive analysis of double arc offset in high-power double-wire DPGMAW. Journal of Manufacturing Processes 49: 423-437. DOI: 10.1016/j.jmapro.2019.10.022

17. Asai, S., Ogawa, T., Ishizaki, Y., Minemura, T., Minami, H., and Iyazaki, S. M. 2012. Application of plasma MIG hybrid welding to dissimilar joints between copper and steel. Welding in the World 56(1-2): 37-42. DOI: 10.1007/bf03321143

18. Cai, D. T., Han, S. G., Zheng, S. D., Luo, Z. Y., Zhang, Y. P., and Wang, K. 2018. Microstructure and corrosion resistance of Al5083 alloy hybrid plasma-MIG welds. Journal of Materials Processing Technology 255: 530-535. DOI: 10.1016/j.jmatprotec.2017. 12.033

19. Guo, Y. Y., Pan, H. H., Ren, L. B., and Quan, G. F. 2018. An investigation on plasma-MIG hybrid welding of 5083 aluminum alloy. International Journal of Advanced Manufacturing Technology 98(5-8): 1433-1440. DOI: 10.1007/s00170-018-2206-4

20. Bai, Y., Gao, H. M., Wu, L., Ma, Z. H., and Cao, N. Influence of plasma-MIG welding parameters on aluminum weld porosity by orthogonal test. Transactions of Nonferrous Metals Society of China 20(8): 1392-1396. DOI: 10.1016/s1003-6326(09)60310-1

21. Ono, K., Liu, Z. J., Era, T., Uezono, T., Ueyama, T., Tanaka, M., and Nakata, K. 2009. Development of a plasma MIG welding system for aluminium. Welding International 23(11): 805-809. DOI: 10.1080/09507110902836945

22. Bai, Y., Gao, H. M., and Qiu, L. 2010. Droplet transition for plasma-MIG welding on aluminium alloys. Transactions of Nonferrous Metals Society of China 20(12): 2234-2239. DOI: 10.1016/ s1003-6326(10)60634-6

23. Hertel, M., Füssel, U., and Schnick, M. 2014. Numerical simulation of the plasma-MIG process-interactions of the arcs, droplet detachment and weld pool formation. Welding in the World 58(1): 85-92. DOI: 10.1007/s40194-013-0095-6

24. Yang, T., Chen, H., Zhuang, Y., Xiong, J., Gao, H. M., and Chen, Y. 2016. Research on properties of arcs interaction for plasma-MIG hybrid arc welding process. Journal of Computational and Theoretical Nanoscience 13(4): 2407-2412. DOI: 10.1166/jctn. 2016.4594

25. Yang, T., Gao, H. M., Zhang, S. H., and Wu, L. 2013. Interface behavior of copper and steel by plasma-MIG hybrid arc welding. Acta Metallurgica Sinica (English Letters) 26(3): 328-332. DOI: 10.1007/s40195-012-0159-4

26. Lee, H. K., Chun, K. S., Park, S. H., and Kang, C. Y. 2015. Control of surface defects on plasma-MIG hybrid welds in cryogenic aluminum alloys. International Journal of Naval Architecture and Ocean Engineering 7(4): 770-783. DOI: 10.1515/ijnaoe-20150054

27. Shan, S. Y., Jia, Q. M., Jiang, L. H., Wang, Y. M., and Yang, J. F. 2009. Microstructure control and mechanical properties of porous silicon nitride ceramics. Ceramics International 35(8): 3371-3374. DOI: 10.1016/j.ceramint.2009.06.009

JANG YU, HONGTAO ZHANG (zhanght@hitwh.edu.cn), and PENG $H E$ are with State Key Laboratory of Advanced Welding and Joining, Harbin Institute of Technology, Harbin, China. XIAO YANG is with FAW Car Co. Ltd., Changchun, China. YAO TENG, QICHEN WANG, and LIQIN WEI are with Yantai CIMC Raffles Offshore Ltd., Yantai, China. WENIIE ZHANG is with Weihai Donghai Shipyard Co. Ltd., Weihai, China. 